\title{
Assessing pain by facial expression: Facial expression as nexus
}

\author{
Kenneth M Prkachin PhD RPsych
}

\begin{abstract}
KM Prkachin. Assessing pain by facial expression: Facial expression as nexus. Pain Res Manage 2009;14(1):53-58.

The experience of pain is often represented by changes in facial expression. Evidence of pain that is available from facial expression has been the subject of considerable scientific investigation. The present paper reviews the history of pain assessment via facial expression in the context of a model of pain expression as a nexus connecting internal experience with social influence. Evidence about the structure of facial expressions of pain across the lifespan is reviewed. Applications of facial assessment in the study of adult and pediatric pain are also reviewed, focusing on how such techniques facilitate the discovery and articulation of novel phenomena. Emerging applications of facial assessment in clinical settings are also described. Alternative techniques that have the potential to overcome barriers to the application of facial assessment arising out of its resourceintensiveness are described and evaluated, including recent work on computer-based automatic assessment.
\end{abstract}

Key Words: Assessment; Automated assessment; Communication; Facial expression; FACS; Judgment studies; Pain; Pain expression

E volution has equipped us with complex systems for dealing with injury, many of which rely on behaviour. Withdrawal reflexes, for example, exist from the earliest moments and allow us to move away from sources of pain. Healthy adults have language, which allows them to speak about pains, their causes and options for dealing with them. Any attentive parent of a healthy infant can describe behaviours that they use to draw inferences about their child's pain.

Facial expressions are a behavioural source of evidence about pain. Face-to-face interaction with a parent occurs from the earliest moment of existence. Parents monitor their infants' facial expressions, in part because they provide cues to changes in their infants' affective states $(1,2)$. Physical discomfort is of particular interest because only the caretaking adult has the ability to identify the source of distress or to take action when there is a threat to bodily integrity. At this age, facial expression is one of the few behaviours an infant can use to change its world.

Keefe et al (3) described pain behaviour in the following way:

...People who have pain may vocalize their distress by moaning, crying or complaining, or may exhibit painrelated body postures or facial expressions. These verbal and nonverbal behaviors have been called pain behaviors because they serve to communicate the fact that pain is being experienced (emphasis added).

\section{L'évaluation de la douleur par l'expression faciale : L'expression faciale comme lien}

L'expérience de la douleur est souvent représentée par des modifications de l'expression faciale. La nature des indices de douleur que fournit l'expression faciale a fait l'objet de recherches scientifiques considérables. Le présent article passe en revue l'histoire de l'évaluation de la douleur par l'expression faciale selon un modèle d'expression de la douleur qui exprime le lien entre l'expression interne et l'influence sociale. Les auteurs examinent les données sur la structure des expressions faciales de la douleur pendant toute une vie, de même que les applications de l'évaluation de la douleur dans l'étude de la douleur chez l'adulte et l'enfant, d'après l'utilisation de ces techniques pour faciliter la découverte et l'exposition d'un nouveau phénomène. Ils décrivent également les applications émergentes de l'évaluation faciale en milieu clinique. Enfin, ils décrivent et évaluent les autres techniques susceptibles de vaincre les obstacles reliés à l'application de l'évaluation faciale découlant de son exigence en termes de ressources, y compris les récents travaux sur l'évaluation automatique informatisée.

This description emphasizes that pain behaviours are communicative. We can distinguish, however, between direct and indirect communication. Certain behaviours that communicate pain serve primarily to modify it (eg, rubbing an irritated part of the body). Behaviours such as facial expressions appear to be specifically adapted for social communication $(4,5)$. Pain expressions can be defined as salient behaviours, in any modality, that accompany and are specific to pain and appear to be adapted to function in interpersonal contexts. In principle, this definition encompasses other kinds of behaviour, such as vocalizations. Facial expressions' distinct features are the focus here.

\section{HISTORICAL BACKGROUND}

Humans have probably always been sensitive to the facial expression of pain. Artists of the classic era were able to capture the sense of suffering through representations of the face. For example, Laocoön and His Sons, a sculpture depicting the death throes of a Trojan priest, is remarkable for its use of the face to represent agonizing pain. Charles Darwin (6) characterized pain expression thus:

... [in pain] the mouth may be closely compressed, or more commonly, the lips are retracted, with the teeth clenched or ground together...the eyes stare wildly as if in horrified astonishment. 
Darwin's was the first major attempt to place the study of pain expression on a scientific basis. His approach to pain was consistent with his views on emotions in general. He focused on expressive behaviours as a means of understanding the origin and functions of motivational and affective states. The explicit role of nonverbal communication behaviours as functional adaptations was acknowledged. Likewise, he emphasized the concepts of interspecific and ontogenic continuity.

Darwin's contribution to the study of pain expression, like the broader contribution to the study of emotional communication of which it was a part, was largely forgotten for a century. The turn of behavioural science away from universalism and toward cultural relativism that occurred at the cusp of the 20th century was one reason. Other early research (7) questioned the notion that there was anything discrete and universal to be found in facial expression.

Despite the decline in interest, there were occasional forays into the study of facial expression in relation to pain. Hollander (8) studied experimental pain by placing a metal grater under a blood pressure cuff and inflating it, noting the pressure at which the subject 'winced.' Chapman and Jones (9) used heat to evaluate the "pain-reaction". They noted that:

[t]he pain reaction end-point was readily observed by watching for the beginning contraction of the eyelids at the outer canthus...Only a small number [of participants] could make any appreciable alteration...even when asked to keep from wincing as long as possible (9).

These observations are interesting because they implicate the facial region surrounding the eye as carrying important information about pain. They foreshadow later interest in the ability to self-regulate displays of pain. In later work, Chapman (10) noted that, in patients with 'neurosis', the pain reaction occurred at lower stimulus levels than in normal patients. Apart from this early work, studies of pain expression were sporadic and had little influence until the 1970s.

\section{Emergence of interest in pain expression}

Four sources of the re-emergence of interest in pain expression can be identified. First, in the 1970s, psychologists applying the operant model proferred the concept of pain behaviour. This approach noted that almost all inferences about pain arise from observations of behaviour (11) and focused attention on those behaviours. The second was the ongoing search for the 'Holy Grail' of pain measurement. Researchers sought better methods for measuring pain. Then, as now, human studies were largely dependent on verbal reports, despite the long tradition of concerns about their objectivity, susceptibility to bias and validity. As an overt behaviour related to pain experience, facial expression offered a basis for evaluating pain that may have circumvented the problems of self-report and yielded a more 'objective' measure. Early work showed that indexes of facial expression could be sensitive both to variations in pain and variables thought to influence pain (12). The third influence arose from the field of emotion. Research by Ekman et al (13) and Izard (14) supported the conclusion that there is a discrete set of universal, basic emotions identifiable in facial expressions. The fourth and, arguably, most important influence involved advances in methodology.

\section{METHODOLOGICAL ADVANCES}

Facial expressions are complex, evolve over time, and are difficult to describe and quantify. Normally, they leave no record. These difficulties present a formidable barrier to scientific analysis. The relatively recent development of affordable and accessible video technology overcame this problem and stimulated growth of the field.

Technology does not, however, resolve the problem of quantification. The major advance that addressed this problem was the development of observational systems that were clearly described, minimizing inference and maximizing 'objectivity'. (The word 'objectivity' is in quotation marks because all facial coding systems that are applied by humans involve some element of judgment, with the inherent subjectivity that that entails.) Ekman and Friesen's (15) Facial Action Coding System (FACS) has been the most influential. It makes use of an anatomical and descriptive principle - facial expressions are described in terms of 44 'action units', which are the unique changes produced by individual facial muscles or muscle combinations. Observers work from strict coding criteria to 'dissect' facial movements through repeated review of video recordings.

\section{The first wave: The structure of pain expression}

LeResche (16) used FACS to characterize facial expressions depicted in candid photographs of people undergoing extreme pain. She concluded that there was a characteristic pain expression, involving brow lowering, skin drawn tightly around the eyes, and a horizontally stretched open mouth with deepening of the nasolabial furrow. Craig and Patrick (17) used the FACS to characterize the facial expressions of people responding to the cold pressor test. They reported significant pain-associated increases in six facial action categories: cheekraising/lid-tightening, upper lip raising, lip-corner pulling, lips parting, mouth opening and eye closure/blinking. Patrick et al (18) studied reactions to pain induced by electric shock, and reported a significant increase in brow lowering, in addition to the aforementioned movements, to be associated with increased pain.

The relative consistency with which the same actions were associated with pain in these studies supported the concept of a characteristic, possibly universal 'pain expression'. The concept of universality implies consistency across painful stimuli and cultures. Prkachin (19) examined the first issue, using FACS to measure facial responses to four categories of nociceptive stimulation: cold, pressure, ischemia and electric shock. This study demonstrated significant increases in four actions - brow lowering, orbit tightening, upper-lip raising/ nose wrinkling, and eye closure - across all four types of stimulation. Certain actions that had been associated with pain in other studies (lip-corner pulling and blinking) were only associated with some categories of pain. The results appeared to support the conclusion that there is a basic pain signal involving four 'core' facial actions. This issue has been revisited recently in a study of patients suffering from shoulder pain exposed to numerous potentially painful clinical range-of-motion tests (20). Principal component analyses indicated that the aforementioned 'core' actions comprised the only consistent responses, loading 0.30 or greater across all pain tests. 
TABLE 1

Homology of pain expression across the lifespan

\begin{tabular}{|c|c|c|c|c|}
\hline Muscular basis & Adult (FACS) & Neonate (NFCS) & Child (CFCS) & Elderly (FACS) \\
\hline Corrugator & Brow lower (AU 4) & Brow bulge & Brow lower & \\
\hline Orbicularis oculi & $\begin{array}{l}\text { Lids tighten, cheek raise } \\
\text { (AU 6, AU 7) }\end{array}$ & Eye squeeze & $\begin{array}{l}\text { Eye squeeze, squint, cheek } \\
\text { raiser }\end{array}$ & $\begin{array}{l}\text { Lids tighten, cheek raise } \\
(A \cup 6, A \cup 7)\end{array}$ \\
\hline \multirow[t]{2}{*}{ Levator } & 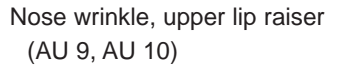 & $\begin{array}{l}\text { Nasolabial furrow, vertical } \\
\text { mouth stretch }\end{array}$ & $\begin{array}{l}\text { Nose wrinkler, nasolabial } \\
\text { furrow, upper lip raiser }\end{array}$ & $\begin{array}{l}\text { Nose wrinkler, lip raiser } \\
\quad(A \cup 9, A \cup 10)\end{array}$ \\
\hline & Eyes close & & & \\
\hline Zygomatic & Lip corner pull (AU 12) & Lip corner puller & & Lip corner pull (AU 12) \\
\hline Risorius & $\begin{array}{l}\text { Horizontal mouth stretch } \\
\text { (AU 20) }\end{array}$ & & Horizontal mouth stretch & \\
\hline Pterygoid & & & Vertical mouth stretch & \\
\hline Mentalis & & Chin quiver & & \\
\hline Nasalis & & & Flared nostril & \\
\hline
\end{tabular}

Descriptors are from the system used to code expressions. AU Facial Action Coding System (FACS) action unit; CFCS Child Facial Coding System; NFCS Neonatal Facial Coding System. Data from references 19-21,23

\section{Pain expression in children}

Investigators interested in studying facial expressions of children must confront the problem that, because of differences in skin texture, the relative absence of permanent features such as creases and wrinkles and aspects of the maturity of neuromuscular systems, the facial actions of children differ from those of adults. Grunau and Craig (21) developed a new measure of potential pain-related actions in neonates: the Neonatal Facial Coding System (NFCS). The NFCS identifies nine specific facial movements: brow bulge, eye squeeze, nasolabial furrow deepen, open lips, vertical mouth stretch, horizontal mouth stretch, lip purse, taut tongue and chin quiver. Measurements of facial activity were taken during lancing of the heel to draw blood samples for phenylketonuria screening. Heel lancing was associated with brow bulging, eye squeezing, nasolabial furrow deepening, lip parting and taut tongue.

A hybrid technique, the Child Facial Coding System (CFCS) (22) was developed to evaluate facial expressions in preschool children. The CFCS has codes for 13 facial behaviours. Gilbert et al (23) applied the CFCS in a study of 13- to 74-month-old children recovering from surgery. Principal components analysis resulted in a single factor solution, with the following actions loading at 0.60 or higher: cheek raiser, nasolabial furrow, vertical mouth stretch, brow lower, flared nostril, squint, nose wrinkler, eye squeeze, horizontal mouth stretch and lip corner puller. Similar findings have been reported among children undergoing immunizations (24).

The striking similarities between the actions that have been associated with pain in adults, children and neonates suggests that they constitute a homologous signal with continuity from the earliest days of life to adulthood. In a study of responses of young ( 20 to 38 years of age) and elderly (65 to 85 years of age) volunteers to mechanical and electric stimulation, both types of pain were associated with increases in orbit tightening and levator contraction (25). Mechanical pain was also associated with increases in brow lowering. In short, the evidence that there is a common facial response to different types of pain extending across the life span seems strong (Table 1).

These findings imply that the bulk of the information about pain contained in facial expression arises from a limited set of facial actions, notably those produced by corrugator, orbicularis oculi and levator muscles. Other actions may be recruited, but their occurrence is less reliable. Fundamentally, this suggests that investigators interested in assessing pain expression can safely limit their attention to these actions without missing information of key importance.

\section{The next wave}

Identifying relevant facial behaviours and establishing their validity is an important endeavour, but limited as a goal in itself. Added value would accrue if windows on new phenomena or new interpretations were opened. This promise has begun to be realized in a number of areas, only a sampling of which can be given here.

A common question about the value of facial measurement is why it should be used if simpler, alternative methods are available and adequate. Indeed, it is commonly argued that verbal report is the 'gold standard' for pain assessment, although this argument has been criticized (26). Of course, facial expression may be one of few alternatives available in those significant instances in which verbal report is unavailable, as is the case with neonates, infants and young children, or people with verbal communication deficits (27). Even when verbal report is available, however, assessment of facial expression of pain brings added value.

For example, in a recent study (28), responses to five levels of mechanical pain were studied in patients with dementia and controls. Participants rated the pain verbally and their facial expressions were measured using FACS. Verbal ratings of pain did not differentiate the experience of patients and controls; however, measurement of pain expression revealed a distinctly different, enhanced dose-response relationship between level of stimulation and pain expression. This finding identifies a novel phenomenon - enhanced pain reactivity among those with dementia - the existence of which would not have been known had the investigators relied only on verbal report.

Developmentally, pain expression reflects the interplay among complex constitutional, experiential and environmental forces. Investigations that incorporate assessment of pain expression provide the opportunity to describe and understand such forces. In one study (29), the intensity of pain expression among five-year-old children undergoing immunization was measured. Individual differences in pain reactivity were significantly related to parents' reports of their children's 
somatization. In a follow-up of this sample, pain reactivity at five years of age was associated with the children's own selfreports of somatic symptoms at 11 to 12 years of age (30). These findings suggest that the intensity of pain expression in the early years of life may serve as a marker of resilience and vulnerability processes.

\section{Applications in special populations}

Facial behaviour provides an important window into the pain experience of populations who have difficulty using language to communicate about pain. Preverbal children are one such population, but others have been the focus of study. Although direct behavioural observation of facial expression in such populations is the gold standard by which facial actions linked to pain should be inferred, several assessment instruments have been developed that make use of reports on behaviour. For example, the Noncommunicating Children's Pain Checklist (31) was developed to assess pain in children with verbal communication impairments. Behaviours that parents of cognitively impaired children reported observing during episodes of pain were incorporated, including five categories of facial expression: furrowed brow, changing appearance around the eyes, turning down of mouth, lip changes and clenching, and grinding teeth and tongue activity. Caregivers of children with such problems as dysmorphic syndrome, extreme prematurity and asphyxia at birth, completed diaries in which they reported on pain episodes that occurred in their children in the natural environment. The scale was able to discriminate well between painful and nonpainful episodes. Facial actions contributed significantly to these distinctions.

Facial expression has also been able to provide insight into the experience of children at risk of a variety of conditions. In one study (32), the NFCS was used to study the influence of previous pain experiences on pain reactivity among infants with low birth weights undergoing heel lance at 32 to 33 weeks postconceptional age. Infants who received a greater number of painful procedures, who were judged to have more severe illnesses and who had been administered higher levels of exogenous steroids, showed diminished reactivity to the test stimulus. Stevens et al (33) studied neonates admitted to tertiary neonatal intensive care units. Three cohorts were defined according to their risk of neurological impairment: conditions such as respiratory distress or sepsis (low risk); pulmonary hypertension, meningitis or necrotizing enterocolitis (intermediate risk); and perinatal asphyxia (high risk). Facial actions in response to heel lancing for blood sampling were measured with the NFCS. All three cohorts displayed increases in pain expression following exposure to the heel lance procedure. Both the intermediate and high risk of neurological impairment cohorts displayed diminished facial responsiveness, suggesting either that the cohorts differed in their pain experience or that risk of neurological impairment carries with it risk of diminished ability to express pain.

\section{Clinical application}

For the most part, measurement of pain expression has been limited to research investigations because of its resourceintensive nature. Nevertheless, investigators have worked toward the development of systems for making routine observations of facial behaviour during pain that can be used in clinical settings. Observers have been trained to perform real-time measurement of pain expression during physical examinations of low-back pain patients (34). In children, the NFCS has been applied to real-time assessment of 32- to 33-week postconceptional age infants undergoing heel lance (35). Reliability of observations was high, with four movements (brow lower, eye squeeze, nasolabial furrow deepen and open mouth) showing clear discrimination between painful and nonpainful phases of the procedure.

Preterm infants are at particular risk of suffering consequences of exposure to pain because they are often subjected to invasive medical interventions. Difficulties for assessment arise because there is evidence that facial pain expression is diminished in preterm infants (32). Holsti and Grunau (36) developed an adapted instrument for assessing pain behaviours in preterm infants, the Behavioural Indicators of Infant Pain scale, by combining reliably pain-associated facial actions from the NFCS with sleep/wake indicators and hand movements (splaying and making a fist). The Behavioural Indicators of Infant Pain was applied in real time to video recordings of preterm infants as they underwent heel lancing. This scale was applied reliably by experienced and inexperienced raters. It effectively differentiated painful from nonpainful phases of the procedure.

Given the ready availability of video recording equipment and evidence of the reliability of the procedures, these studies suggest that real-time, clinical applications are possible and feasible.

\section{Limitations of facial measurement, alternatives and new directions}

Despite evidence of their value in a variety of populations, facial measures have historically been of interest to a small group of scientists and clinicians (37). The main reason is that pain assessment by facial expression is burdensome. If measurement is based on the FACS, there is a considerable amount of time (approximately $100 \mathrm{~h}$ ) involved in training. Observation is dependent on access to hardware and software for performing frame-by-frame analysis. Then there is the significant issue of the time required for observation. If the full FACS procedure is used, a reasonable estimate is that for every unit of real time, coding requires 100 units. Based on what has been learned, it is now possible to restrict attention to a smaller number of facial actions. Even so, coding can still consume many multiples of the real time involved in the behaviour.

There are other limitations to facial coding techniques. Often characterized as 'objective', they are based, in the final analysis, on human judgments. Anyone who has performed facial measurement using these procedures realizes that there are elements of subjectivity in deciding when an action has occurred or when it meets the minimum requirements for coding. In addition, the human observer has inherent limitations in his or her capacity to make precise discriminations at the margins. Alternatives exist or are in development.

Judgment studies: A relatively simple alternative is the judgment study (38). In a judgment study, untrained judges rate some underlying dimension of the behaviour. For example, samples of the facial responses of children to a potentially painful event may be edited from video recordings and presented to judges to rate on a scale of pain intensity. The judgments of observers in such studies are often highly reliable (39) and can 
be aggregated into overall scores that represent the intensity of the reaction.

Properly designed, such studies have the advantage that they can give additional insight into the social component of the pain-expression nexus. Such methods have been valuable in shedding light on the commonly observed underestimation bias in pain judgments: the fact that observers, including health care providers, often underestimate others' pain, when the criterion is the pain reports of others. For example, it has been shown that the experience of viewing high levels of pain in others makes observers less willing to judge others as in pain, while leaving unaffected their ability to tell the difference between pain of different intensities (40). Using similar methodology, evidence that children as young as five years of age are already sensitive to pain in others and capable of making quantitative distinctions has been presented (41).

\section{Automated analysis}

If there is a configuration of facial actions that signals pain, then assessing its presence reduces to a problem of pattern recognition. Information technology approaches hold considerable promise to advance this area. Indeed, substantial progress has been made toward the development of computer-based automated analysis of facial expression (41). Recently, the performance of such a system in detecting pain-related facial actions among a sample of patients undergoing range-ofmotion testing to assess shoulder pain has been examined (42). Digital videos containing pain expressions and control videos were processed using Active Appearance Models $(43,44)$, a technique that allows variations in the shape and appearance of the face to be separated. Machine learning procedures were then used to train a system for rendering predictions of pain versus no pain. A hit rate of $83 \%$, with a false alarm rate of $30 \%$ was obtained with the best performing predictive model. A particular advantage of this technique is its ability to represent dynamic changes in pain-related actions, which can provide insight into motor control processes involved in regulating pain expression.

Recently, Schiavenato et al (45) reported on an alternative information technology-based approach: the point-pair method. Individual video frames depicting neonates before and after undergoing heel lancing were selected. Landmarks corresponding to NFCS actions were identified, and standardized distances between pairs of points were compared. Results were consistent with behavioural studies showing major painassociated differences consistent with mouth opening, brow lowering and orbit tightening.

Information technology-based systems are currently relatively primitive, but there is little doubt that their use in assessing pain expression is feasible and their capacities will become more powerful with further research.

\section{SUMMARY}

Active investigations of facial expressions of pain began in the 1970s. Research using direct measurement methods has identified characteristic changes that appear to be homologous across the lifespan. Studies that have made use of direct measurement have established novel insights into pain in adults and children, while studies that have relied on dimensional judgments have also contributed to our understanding of how pain behaviour is processed and acted on by others. Although facial assessment has historically been resource-intensive, new developments, including real-time assessment protocols and computer-visionassisted automated assessment promise to advance understanding of pain in clinical and research settings.

ACKNOWLEDGEMENTS: The author's research described in this paper was supported by grants from the Canadian Institutes of Health Research. I thank Jeff Cohn for helpful commentary on a previous draft.

\section{REFERENCES}

1. Lewis MJ, Allesandri SM, Sullivan MW. Violation of expectancy, loss of control and anger expressions in young infants. Dev Psychol 1990;26:745-51.

2. Rosenstein D, Oster H. Differential facial expressions to four basic tastes in newborns. Child Dev 1988;59:1555-68.

3. Keefe FJ, Williams DA, Smith SJ. Assessment of pain behaviors. In: Turk DC, Melzack R, eds. Handbook of Pain Assessment, 2nd edn. New York: Guilford, 2001:170-87.

4. Prkachin KM. Pain behaviour is not unitary. Behav Brain Sci 1986;9:754-5.

5. Williams AC. Facial expression of pain: An evolutionary account. Behav Brain Sci 2002;25:439-88.

6. Darwin C. The expression of emotion in man and animals. New York: Philosophical library, 1872/1955.

7. Landis C. The interpretation of facial expression in emotion. J Gen Psychol 1929;2:59-72.

8. Hollander E. A clinical gauge for sensitivity to pain. J Lab Clin Med 1939;24:537.

9. Chapman WP, Jones CM. Variations in cutaneous and visceral pain sensitivity in normal subjects. J Clin Invest 1944;23:81-91.

10. Chapman WP. Measurements of pain sensitivity in normal control subjects and in psychoneurotic patients. J Psychosom Med 1944;6:252-7.

11. Fordyce WE. Behavioral Methods for Chronic Pain and Illness. St Louis: Mosby, 1976.

12. Prkachin KM, Craig KD. Influencing nonverbal expressions of pain: Signal detection analyses. Pain 1985;21:399-409.

13. Ekman P, Sorenson ER, Friesen WV. Pan-cultural elements in facial displays of emotion. Science 1969;164:86-8.

14. Izard CE. The Face of Emotion. New York: Appleton-CenturyCrofts, 1971.

15. Ekman P, Friesen WV. Manual for the Facial Action Coding System. Palo Alto: Consulting Psychologists Press, 1978.

16. LeResche L. Facial expression in pain: A survey of candid photographs. J Nonverbal Behav 1982:7:45-56.

17. Craig KD, Patrick CJ. Facial expression during induced pain. J Pers Soc Psychol 1985;48:1080-91.

18. Patrick CJ, Craig KD, Prkachin KM. Observer judgments of acute pain: Facial action determinants. J Pers Soc Psychol 1986;50:1291-8.

19. Prkachin KM. The consistency of facial expressions of pain: A comparison across modalities. Pain 1992;51:297-306.

20. Prkachin KM, Solomon PE. The structure, reliability and validity of pain expression: Evidence from patients with shoulder pain. Pain 2008;139:267-74.

21. Grunau RV, Craig KD. Pain expression in neonates: Facial action and cry. Pain 1987;28:395-410.

22. Chambers CT, Cassidy KL, McGrath PJ, et al. Child Facial Coding System: A Manual. Nova Scotia and Vancouver: Dalhousie University and University of British Columbia, 1996.

23. Gilbert CA, Lilley CM, Craig KD, et al. Postoperative pain expression in preschool childen: Validation of the Child Facial Coding System. Clin J Pain 1999;15:192-200.

24. Breau LM, McGrath PJ, Craig KD, Santor D, Cassidy K-L, Reid GJ. Facial expression of children receiving immunizations: A principal components analysis of the Child Facial Coding System. Clin J Pain 2001;17:178-86.

25. Kunz M, Mylius V, Schepelmann K, Lautenbacher S. Impact of age on the facial expression of pain. J Psychosom Res 2008;64:311-8.

26. Hadjistavropoulos T, Craig KD. Social influences and the communication of pain. In: Hadjistavropoulos T, Craig KD, eds. Pain: Psychological Perspectives. New York: Erlbaum, 2004:87-112. 
27. Craig KD, Prkachin KM, Grunau RV. The facial expression of pain. In: Turk DC, Melzack R, eds. Handbook of Pain Assessment. New York: Guilford, 1993.

28. Kunz M, Scharmann S, Hemmeter U, Schepelmann K, Lautenbacher $\mathrm{S}$. The facial expression of pain in patients with dementia. Pain 2007;133:221-8.

29. Rocha E, Prkachin KM, Beaumont SL, Hardy C, Zumbo BD. Pain reactivity and illness behavior in kindergarten-aged children. J Pediatr Psychol 2003;28:47-57.

30. Rocha E, Prkachin KM. Temperament and pain reactivity predict health behavior seven years later. J Pediatr Psychol 2007;32:393-9.

31. Breau LM, McGrath PJ, Camfield CS, Finley GA. Psychometric properties of the non-communicating children's pain checklistrevised. Pain 2002;99:349-57.

32. Grunau RE, Oberlander TF, Whitfield MF, Fitzgerald C, Lee SK. Demographic and therapeutic determinants of pain reactivity in very low birth weight neonates at 32 weeks' postconceptional age. Pediatrics 2001;107:105-12.

33. Stevens B, McGrath P, Gibbins S, et al. Determining behavioural and physiological responses to pain in infants at risk for neurological impairment. Pain 2007;127:94-102.

34. Prkachin KM, Hughes EA, Schultz I, Joy P, Hunt D. Real-time assessment of pain behavior during clinical assessment of low-back pain patients. Pain 2002;95:23-30.

35. Grunau RE, Oberlander T, Holsti L, Whitfield MF. Bedside application of the Neonatal Facial Coding System in pain assessment of premature neonates. Pain 1998;76:277-86.
36. Holsti L, Grunau RE. Initial validation of the Behavioral Indicators of Infant Pain (BIIP). Pain 2007;132:264-72.

37. Prkachin KM. The coming of age of pain expression. Pain 2007;133:3-4.

38. Rosenthal R. Judgment Studies: Design, Analysis and Meta-analysis. Cambridge: Cambridge University Press, 1993.

39. Prkachin KM, Berzins S, Mercer SR. Encoding and decoding of pain expressions: A judgement study. Pain 1994;58:253-9.

40. Prkachin KM, Mass H, Mercer SR. Effects of exposure on perception of pain expression. Pain 2004:111:8-12.

41. Deyo K, Prkachin KM, Mercer SR. Development of sensitivity to facial expressions of pain. Pain 2004;107:16-21.

42. Tian Y, Cohn JF, Kanade T. Facial expression analysis. In: Li SZ, Jain AK, eds. Handbook of Face Recognition. New York: Springer, 2005:247-76.

43. Ashraf AB, Lucey S, Cohn JF, et al. The painful face: Pain expression recognition using active appearance models. Proceedings of the ACM International Conference on Multimodal Interfaces, 2007:9-14

44. Lucey S, Matthews I, Hu C, Ambadar Z, De la Torre F, Cohn JF. AAM derived face representations for robust facial action recognition. Seventh IEEE International Conference on Automatic Face and Gesture Recognition, FG2006, 2006:155-60.

45. Schiavenato M, Byers JF, Scovaner P, et al. Neonatal pain facial expression: Evaluating the primal face of pain. Pain 2008;138:460-71. 


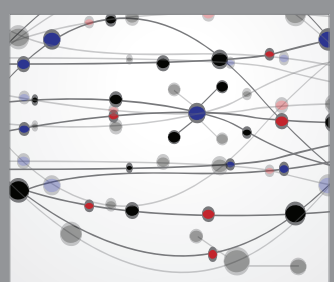

The Scientific World Journal
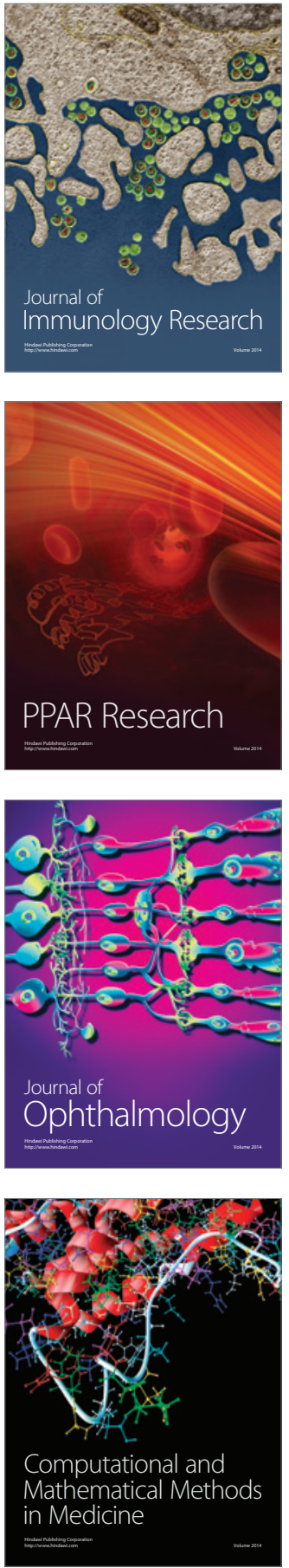

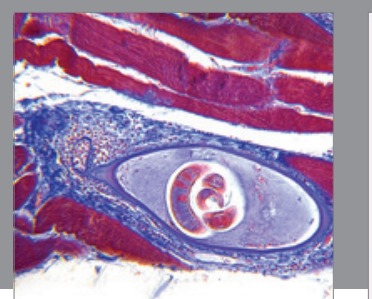

Gastroenterology Research and Practice

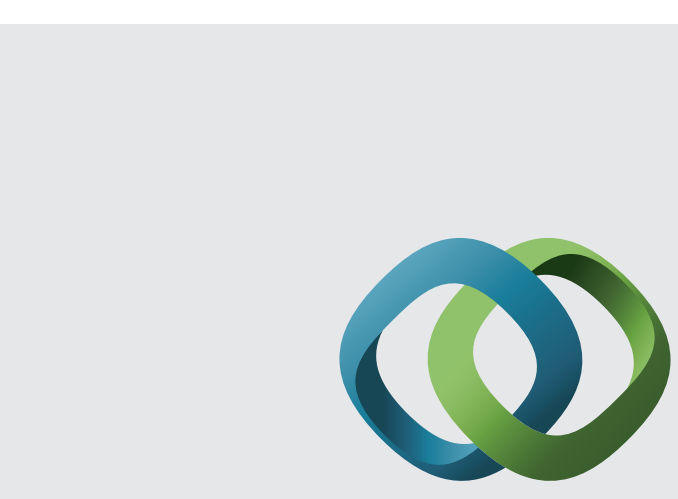

\section{Hindawi}

Submit your manuscripts at

http://www.hindawi.com
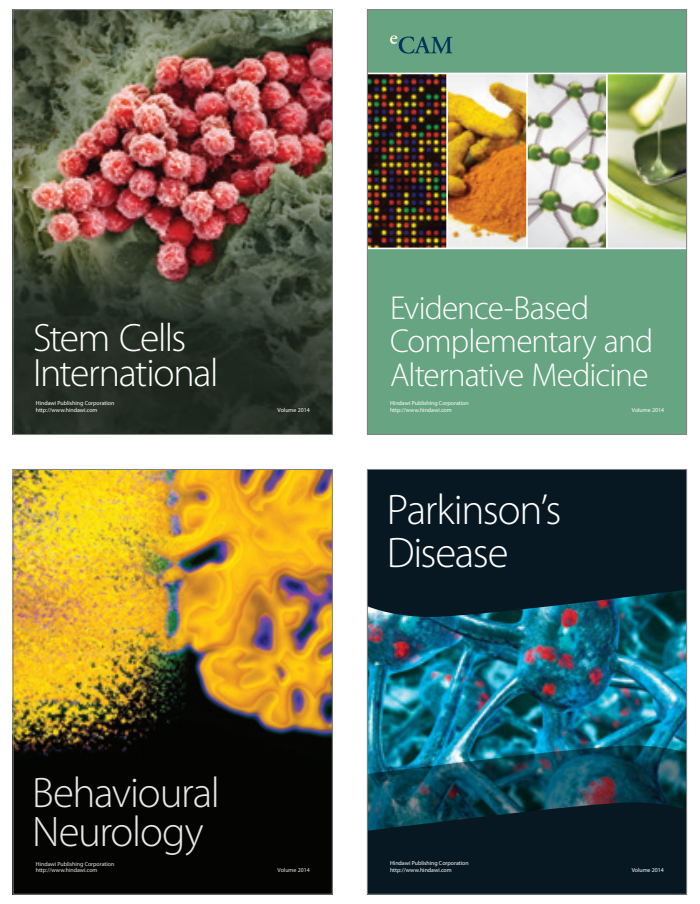
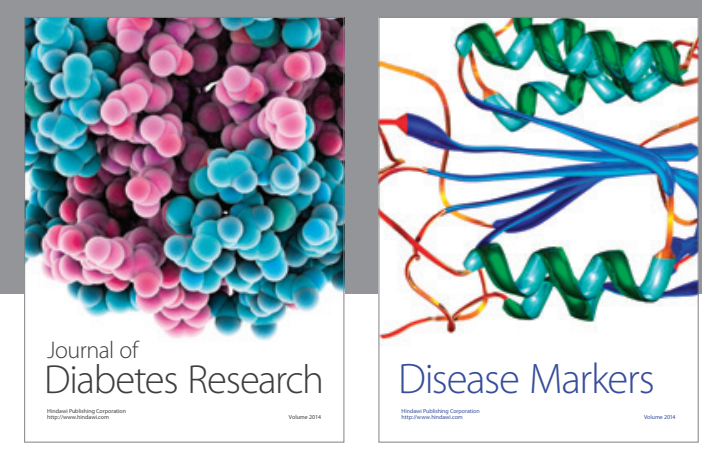

Disease Markers
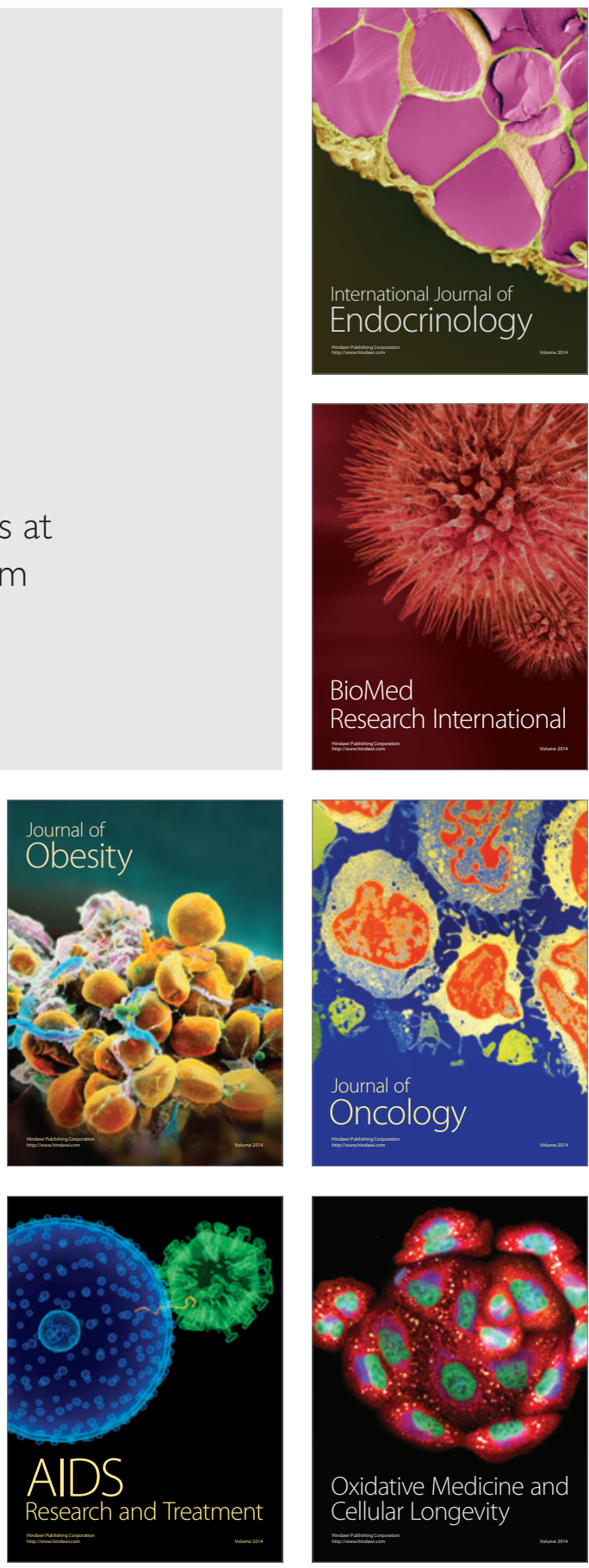